\title{
Implicações da redistribuição das petro- rendas no Brasil: entre a caixa-preta e o desenvolvimento regional ${ }^{1}$
}

Alcione Talaska

Doutorando do Programa de Pós-Graduação em Desenvolvimento Regional da Universidade de Santa Cruz do Sul

(Unisc)

Péricles Purper Thiele

Doutorando do Programa de Pós-Graduação em Desenvolvimento Regional da Universidade de Santa Cruz do Sul

(Unisc)

Almir Arantes

Faculdade de Educação da Universidade do Estado de Mato Grosso (Unemat)

José Antonio Assump̧̧ão Farias

Centro de Ciências Sociais e Aplicadas do Colégio Estadual Emílio Zuñeda (Ceez)

Camila Talaska

Graduanda em Enfermagem pela Universidade do Estado de Santa Catarina (Udesc)

Luana Köbler Louzado

Mestranda do Programa de Pós-Graduação em Desenvolvimento Regional da Universidade de Santa Cruz do Sul

(Unisc)

Recebido: 26/09/2013 Versão revisada (entregue): 07/04/2014 Aprovado: 26/05/2014

\section{Resumo}

Este texto traz uma contribuição ao debate sobre a distribuição dos royalties e compensações financeiras no Brasil. Aborda, sobretudo, a questão dos royalties do petróleo, trazendo, em um primeiro momento, uma análise dos municípios da região Norte Fluminense, apontando elementos que caracterizam a região frente ao montante de royalties recebidos (petro-rendas) e aos índices de desenvolvimento alcançados. Num segundo momento, considerando as discussões atuais sobre o processo de redistribuição ou distribuição mais equitativa dos recursos dos royalties à sociedade brasileira, contextualiza-se, por meio da Lei 12.744/2012, as consequentes perdas ou ganhos orçamentários dos municípios e estados brasileiros. Para além

${ }^{1}$ Uma versão preliminar deste trabalho foi apresentada no VI Seminário Internacional sobre Desenvolvimento Regional, realizado em setembro de 2013 em Santa Cruz do Sul/RS. 
disso, procura-se articular, na terceira parte desse trabalho, uma discussão sobre a utilização das petro-rendas e o desenvolvimento regional, através da construção de um projeto de desenvolvimento. Conclui-se esse trabalho apontando que o crescimento das receitas orçamentárias municipais ou regionais não se reproduz, necessariamente, em desenvolvimento e que o desenvolvimento regional pressupõe a ideia da região autoconstruir-se, num processo que necessita construção social e política.

Palavras-chave | Desenvolvimento regional; petro-rendas; redistribuição dos royalties; território.

Código JEL | L71; O13; R58.

\title{
IMPLICATIONS OF THE REDISTRIBUTION OF OIL REVENUES IN BRAZIL: BETWEEN THE BLACK BOX AND THE REGIONAL DEVELOPMENT
}

\begin{abstract}
This text brings a contribution to the debate on the redistribution of royalties and financial compensation in Brazil. It especially approaches the issue of oil royalties, bringing initially an analysis of the northern municipalities of the State of Rio de Janeiro, pointing out elements which feature the region in comparison to the amount of royalties received (oil revenues) as well as of the indices achieved. In the second part, considering the current discussions on the redistribution/distribution of the funds related to the royalties, we put the consequent budgetary losses and gains of the Brazilian municipalities and states into context through the Law 12.744/2012. Additionally, in the third part, we seek to articulate a discussion on the use of oil revenues and the regional development by building a development project. We conclude indicating that the growth of municipal or regional budgetary revenue doesn't necessarily end up in development, and that the regional development presupposes an idea of the region to build itself in a process that assumes social and political construction.
\end{abstract}

Keywords | Oil revenues; redistribution of royalties; regional development; territory.

JEL-Code | L71; O13; R58.

\section{IMPLICACIONES DE LA REDISTRIBUCIÓN DE LAS PETRO-RENTAS EN BRASIL: ENTRE LA CAJA NEGRA Y EL DESARROLLO REGIONAL}

\section{Resumen}

Este trabajo trae una contribución al debate sobre la distribución de los royalties y las compensaciones financieras en Brasil. Aborda principalmente el tema de los royalties del petróleo, trayendo, en primer lugar, un análisis de los municipios de la Región Norte Fluminense/RJ, destacando los elementos que caracterizan a la región con relación al total de royalties y compensaciones financieras recibidas (petro-rentas) y de las tasas de desarrollo alcanzados. En segundo lugar, son contextualizadas las consecuentes disminuciones o crecimientos presupuestarios de los municipios y estados brasileños a través de la Ley brasileña 12.744/212 que establece un proceso de distribución más equitativa de los royalties del petróleo para la sociedad brasileña. En la tercera parte del trabajo se busca vincular el debate sobre el uso de las petro-rentas y el desarrollo regional a través de la construcción de un proyecto de desarrollo. El trabajo es concluido señalando que el crecimiento de los ingresos presupuestarios municipales o regionales no se reproduce, necesariamente, en desarrollo, y que el desarrollo regional presupone la idea de que la región se autoconstruya, en un proceso que requiere construcción social y política. 
Palabras-clave | Desarrollo regional; petro-rentas; redistribución de los royalties; territorio.

Código JEL | L71; O13; R58.

\section{Introdução}

A organização da sociedade, com suas marcas econômicas e industriais, evidencia uma busca cada vez mais incessante por energia. Nesse processo, ainda que tenham surgido novas possibilidades de geração e produção energéticas, o petróleo é tido como uma das fontes principais.

A atividade petrolífera, considerando a história de seu desenvolvimento no Brasil, provocou impactos positivos e negativos na paisagem e na organização dos territórios onde se implantou. Se, por um lado, a atividade petrolífera provoca impactos ambientais, com mudanças no ecossistema local/regional, com a modificação da estrutura produtiva ou mesmo com a escassez do recurso explorado, por outro lado, a atividade petrolífera aufere realidades orçamentárias privilegiadas a determinados municípios e estados brasileiros.

Essa realidade privilegiada é decorrente da necessidade das empresas especializadas na exploração do petróleo de ressarcir o Estado pela exploração e produção do recurso natural. Isso é realizado por meio do pagamento de royalties, que se tornam uma remuneração à sociedade pela exploração desse recurso não renovável, tornando-se também uma compensação financeira por possíveis impactos que a atividade petrolífera possa causar ao meio ambiente.

Nesse sentido, diante das importantes descobertas de novos campos de petróleo na camada do pré-sal e do aumento da produção brasileira de petróleo, o presente texto aborda o processo de redistribuição ou distribuição mais equitativa dos royalties e compensações financeiras do petróleo à sociedade brasileira.

Primeiramente, realiza-se um resgate histórico e documental com o objetivo de demonstrar o que são os royalties, como o seu pagamento foi instituído no Brasil e como os seus recursos são distribuídos entre os entes da federação. Utilizamos, como exemplo da aplicabilidade dos royalties no território, os municípios que formam a região Norte Fluminense. Dessa forma, apontam-se elementos que caracterizam a região frente ao montante de royalties recebidos e aos índices de desenvolvimento alcançados.

Num segundo momento, considerando as discussões atuais sobre o processo de redistribuição ou distribuição mais equitativa dos recursos dos royalties à sociedade brasileira, contextualiza-se, por meio do Projeto de Lei do Senado $\mathrm{n}^{\mathrm{o}}$ 448/2011 e da Lei 12.744/2012, as consequentes perdas ou ganhos orçamentários dos municípios e estados brasileiros. 
Posteriormente, procura-se demonstrar a complexidade em se alcançar o desenvolvimento. Em virtude disso, busca-se apontar alguns caminhos e elementos que possam contribuir para a construção de um projeto de desenvolvimento regional, considerando, sobretudo, o caso da redistribuição dos royalties do petróleo.

Assim, conclui-se esse trabalho apontando que o crescimento das receitas orçamentárias municipais ou regionais não se reproduz, necessariamente, em desenvolvimento e que o desenvolvimento regional pressupõe a ideia da região autoconstruir-se, num processo que necessita construção social e política.

\section{Royalties e participações especiais}

De acordo o Guia dos Royalties do Petróleo e do Gás Natural (BARBOSA, 2001, p. 12), os royalties são "uma das formas mais antigas de pagamento de direitos. A palavra royalty vem do inglês 'royal, que significa 'da realeza' ou 'relativo ao rei'. Originalmente, era o direito que o rei tinha de receber pagamento pelo uso de minerais em suas terras".

Mais recentemente, o conceito se estendeu a outras atividades, denominando, nesse contexto, também a cobrança, pelo proprietário de determinado registro de patente, pelo uso ou comercialização de um produto, de um processo de produção, de uma marca, entre outros.

Desse modo, os royalties são uma indenização ao proprietário. No caso do petróleo, o seu pagamento se baseia na exploração econômica de um recurso finito, realizada por empresas especializadas, que precisam ressarcir ao Estado por sua exploração e produção. Os royalties, contexto, tornam-se uma remuneração à sociedade pela exploração desses recursos não renováveis, tornando-se também uma compensação financeira por possíveis impactos negativos ao meio ambiente.

A motivação para a cobrança dos royalties, segundo o estudo sobre a aplicação dos royalties petrolíferos no Brasil, publicado pelo Ministério da Fazenda, envolve diversos objetivos. Estes incluem, além da compensação ambiental, o provimento de recursos necessários, aos governos locais e regionais, para o financiamento de investimentos que possibilitem a substituição da geração da riqueza mineral finita. Ou seja, objetivam a disponibilização de receitas orçamentárias para que os municípios busquem a diversificação produtiva, com a finalidade de garantir a capacidade de promover uma dinâmica de desenvolvimento próprio (MINISTÉRIO DA FAZENDA, 200?).

Dessa forma, monetariamente, a concessão dos royalties vem permitindo que alguns poucos municípios trabalhem com realidades orçamentárias substancialmente diferenciadas em relação à realidade da grande maioria dos 
municípios brasileiros. São, como apontado em trabalho anterior, "territórios privilegiados." (TALASKA; SILVEIRA, 2008).

\section{Royalties do petróleo e do gás natural}

Através de uma breve análise histórica, verificamos que os royalties do petróleo foram instituídos no Brasil através da Lei 2.004/1953, que autorizou o governo a constituir a Petrobrás. Por meio dessa Lei, estados e municípios dividiram a alíquota de 5\% sobre a produção do petróleo em terra (no continente). Com a descoberta de petróleo em mar, em 1969, a União também passou a cobrar 5\% sobre essa produção, concentrando esses recursos para si. Em 1985, com a Lei 7.453 e sua regulamentação em 1986, os municípios conquistaram também o direito de receberem os royalties pela exploração do petróleo em mar, ficando a partilha da seguinte forma: 20\% para a União, 60\% para estados e municípios confrontantes com os poços de petróleo, e 20\% para o Fundo Especial do Petróleo (FEP), que os dividia entre todos os entes da Federação. Em 1989, o FEP foi reduzido para 10\%, transferindo os outros $10 \%$ para os Municípios que possuíam instalações de embarque e desembarque de petróleo e gás natural. A partir do ano de 1997, com a aprovação da Lei do Petróleo (Lei 9.478/1997), a cobrança dos royalties é ampliada de 5\% para 10\%, modificando também a base do cálculo, agora, baseada em preços do petróleo no mercado.

Assim, nesse contexto, os royalties pagos pelos concessionários são recolhidos à "Secretaria do Tesouro Nacional, e posteriormente creditados nas contas correntes que os estados e municípios beneficiários mantêm junto ao Banco do Brasil.” (BARBOSA, 2001, p. 44). Através dessas compensações financeiras, alguns municípios brasileiros vivenciaram um rápido crescimento em suas receitas orçamentárias, principalmente após 1998.

A atualidade - e, propriamente, o grande crescimento das receitas orçamentárias municipais e estaduais - da distribuição dos royalties e das participações especiais do petróleo e do gás natural obedece a uma legislação específica, regulamentada pela Agência Nacional do Petróleo (ANP), cuja finalidade é destacada no art. $2^{\circ}$, do Decreto 2.455/98.

A ANP tem por finalidade promover a regulação, a contratação e a fiscalização das atividades econômicas integrantes da indústria do petróleo, de acordo com o estabelecido na legislação, nas diretrizes emanadas do Conselho Nacional de Política Energética - CNPE e em conformidade com os interesses do País. 
Os royalties do petróleo, com base nessa Lei, são calculados mensalmente para cada campo produtor, aplicando-se a alíquota sobre o valor da produção do petróleo, que é de $10 \%$, podendo ser reduzida a 5\%, tendo em vista os riscos geológicos, as expectativas de produção e outros fatores pertinentes, como afirma a ANP. O valor da produção, por sua vez, é obtido multiplicando-se o volume de petróleo produzido durante o mês pelo preço de referência relativo a este mês. Dessa forma, tem-se: Royalties $=($ Alíquota $\mathrm{x}$ (Produção x Preço de Referência) $)$.

A exploração do petróleo e gás natural origina também um tipo especial de royalty. Trata-se das chamadas participações especiais, que são compensações financeiras cobradas dos concessionários nos casos de exploração de campos de petróleo com grandes valores de produção ou alta rentabilidade.

Assim, a distribuição dos royalties e das participações especiais do petróleo e do gás natural é realizada, segundo a ANP, com base na legislação que trata do tema, entre municípios, estados e União. Os municípios produtores em lavras terrestres têm uma margem de arrecadação superior a $15 \%$ do total de royalties pagos, podendo chegar a 30\% se tiverem instalações para transporte do petróleo ou gás natural. Quanto aos municípios confrontantes com lavras em plataforma continental a arrecadação é superior a $22,5 \%$, podendo chegar a $40 \%$ dos royalties, se tiverem instalações para transporte do petróleo ou gás natural em seu território.

\section{Os royalties do petróleo na região Norte Fluminense: a dependência das petro-rendas}

A região Norte Fluminense, estado do Rio de Janeiro, é formada pelos municípios de Campos dos Goytacazes, Carapebus, Cardoso Moreira, Conceição de Macabu, Macaé, Quissamã, São Fidelis, São Francisco de Itabapoana e São João da Barra. No contexto do pagamento e recebimento de royalties e participações especiais decorrentes da exploração do petróleo, estes municípios configuram-se como território privilegiados, visto que estão listados entre os municípios que mais recebem as chamadas petro-rendas no Brasil.

O pagamento das petro-rendas a estes municípios acontece devido a exploração do petróleo na Bacia de Campos - considerada a principal reserva petrolífera da Plataforma Continental Brasileira (Figura 1). 
Figura 1 - Localização da Bacia de Campos

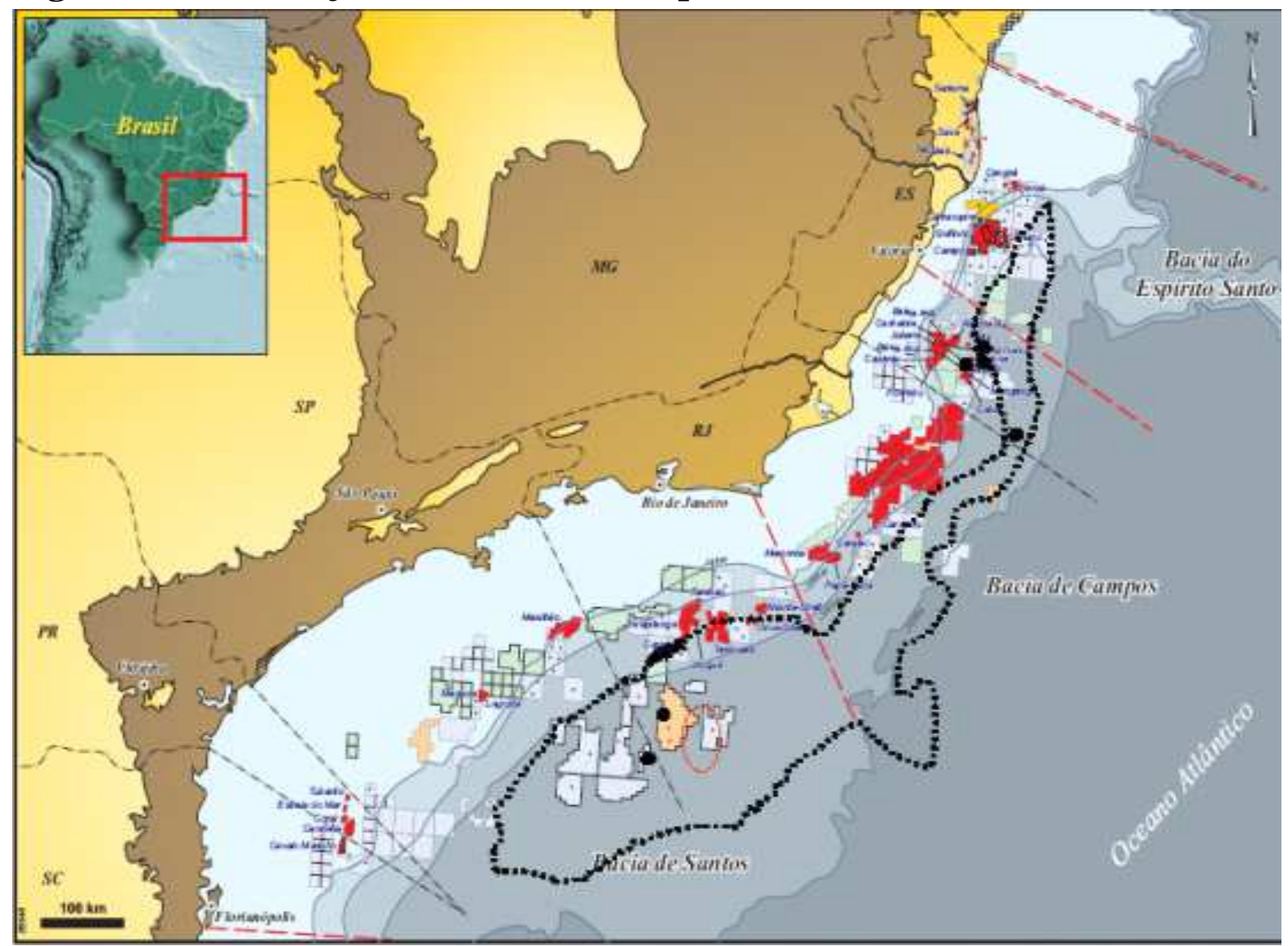

Fonte: IBP (2013).

O complexo extrativista na Bacia de Campos começou a ser implantado em meados da década de 1970, e, de acordo com informações da Petrobras, é a bacia petrolifera que mais produz na margem continental brasileira, correspondendo atualmente a mais de $80 \%$ da produção nacional de petróleo.

Segundo Vianna da Cruz (2005), os royalties e participações especiais transferidos para os nove municípios do norte-fluminense produtores da Bacia de Campos, a título de compensação pela atividade extrativista, totalizam somas bilionárias, situando-os entre os municípios de maior volume de orçamento per capita do país. Dessa forma, proporcionando a estas "prefeituras enorme poder de fogo e autonomia para investimentos nos mais diversos campos das políticas públicas, tais como as políticas urbanas, sociais, e de fomento às atividades econômicas" (VIANNA DA CRUZ, 2005, p. 88).

O montante dos royalties e compensações financeiras recebido pelos municípios da região Norte Fluminense, referentes ao período 1999-2012, estão disponibilizadas na Tabela 1. 
Tabela 1 - Montante de Royalties recebidos, Região Norte Fluminense, 1999-2012

\begin{tabular}{lrr}
\hline \multicolumn{1}{c}{ Município } & $\begin{array}{c}\text { Royalties (Valores } \\
\text { Correntes, em R\$) }\end{array}$ & $\begin{array}{c}\text { Royalties (Valores } \\
\text { Reais*, em R\$) }\end{array}$ \\
\hline Campos dos Goytacazes & $9.862 .688 .984,47$ & $13.336 .837 .906,66$ \\
Carapebus & $349.164 .922,96$ & $507.409 .357,42$ \\
Cardoso Moreira & $44.420 .616,59$ & $64.043 .616,00$ \\
Conceição do Macabu & $51.081 .228,12$ & $73.655 .057,22$ \\
Macaé & $4.413 .933 .386,25$ & $6.156 .724 .668,25$ \\
Quissamã & $1.076 .123 .235,65$ & $1.536 .202 .204,57$ \\
São Francisco de Itabapoana & $61.786 .201,64$ & $91.461 .340,65$ \\
São Fidélis & $60.795 .118,84$ & $87.844 .775,83$ \\
São João da Barra & $1.270 .528 .737,08$ & $1.591 .532 .382,87$ \\
\hline Total Região Norte & $17.190 .522 .431,60$ & $23.445 .711 .309,47$ \\
Fluminense & & \\
\hline
\end{tabular}

* Valores reais corrigidos pelo INPC.

Fonte: Banco de Dados InfoRoyalties (2013), a partir de Agência Nacional do Petróleo.

Com base nas informações trazidas na tabela, observa-se que o montante dos valores recebidos pelos municípios é realmente substancioso, ultrapassando a soma de 17 bilhões de reais em valores correntes e de 23 bilhões de reais em valores reais, corrigidos pelo Índice Nacional de Preços ao Consumidor (INPC). Destacam-se no recebimento dos royalties os municípios de Campos dos Goytacazes, Macaé, São João da Barra e Quissamã, juntos ultrapassando a cifra de 1 bilhão de reais recebidos no período.

Considerando-se o montante dos royalties recebidos no ano de 2012 e a população oficial contabilizada pelo IBGE em 2010, verifica-se, nesse contexto, que as petro-rendas per capita dos municípios da Região Norte Fluminense/RJ confirmam a realidade privilegiada desses territórios. O município de São João da Barra, por exemplo, com população de 32.767 mil habitantes (IBGE, 2010) e tendo recebido $\mathrm{R} \$ 233.262 .154,92$ (ANP, 2013) decorrentes das petro-rendas, perfaz uma média de $\mathrm{R} \$ 7.118,81$ per capita/ano em royalties e participações especiais do petróleo. Essa realidade de elevada recebimento de petro-rendas per capita pode ser verificada também nos municípios de Quissamã ( $\$$ 5.283,53 per capita/ano), Campos dos Goytacazes ( $\mathrm{R} \$ 2.921,47$ per capita/ano), Carapebus ( $\mathrm{R} \$$ 2.894,83 per capita/ano) e Macaé ( $\mathrm{R} \$ 2.605,37$ per capita/ano). Os demais municípios da região apresentaram recebimento de petro-rendas per capita/anual inferior a $\mathrm{R} \$ 500,00$.

A primeira vista, pelo fato de os royalties se tornarem renda adicional ao orçamento municipal, poder-se-ia deduzir que esses municípios tenderiam a possuir índices de desenvolvimento muito elevados, figurando entre os mais 
desenvolvidos do país. Contrariamente, a dedução não é totalmente verdadeira. Vianna da Cruz (2005, p. 51), em texto publicado no ano de 2005, já afirmava que esses municípios aparecem no "cenário nacional como destaque negativo nos índices que medem o desenvolvimento humano e social, a socioeconomia e a qualidade de vida", visto que apresentam elevados índices de desigualdades de renda, desemprego e pobreza.

Nesse contexto, a Tabela 2 apresenta uma comparação entre os índices de desenvolvimento desses municípios em 2000, ano próximo àquele em que os municípios começaram a receber somas mais substanciosas de royalties, e 2010. Utiliza-se para a análise o Índice Firjan de Desenvolvimento Municipal (IFDM), por ele ser construído inspirado no Índice de Desenvolvimento Humano (IDH) e possibilitar a realização da comparação entre estes dois momentos distintos.

\section{Tabela 2 - Índice Firjan de Desenvolvimento Municipal (IFDM)}

\begin{tabular}{lrrrr}
\hline \multirow{2}{*}{ Região Norte Fluminense } & \multicolumn{2}{c}{ IFDM } & \multicolumn{2}{c}{ IFDM } \\
\cline { 2 - 5 } & 2000 & 2010 & 2000 & 2010 \\
\hline Campos dos Goytacazes & 0,68 & 0,75 & $596^{\circ}$ & $752^{\circ}$ \\
Carapebus & 0,57 & 0,70 & $2.061^{\circ}$ & $1.692^{\circ}$ \\
Cardoso Moreira & 0,61 & 0,69 & $1.489^{\circ}$ & $1.764^{\circ}$ \\
Conceição do Macabu & 0,65 & 0,62 & $918^{\circ}$ & $3.294^{\circ}$ \\
Macaé & 0,78 & 0,83 & $45^{\circ}$ & $174^{\circ}$ \\
Quissamã & 0,64 & 0,74 & $1.051^{\circ}$ & $584^{\circ}$ \\
São Francisco de Itabapoana & 0,55 & 0,65 & $2.330^{\circ}$ & $2.739^{\circ}$ \\
São Fidélis & 0,61 & 0,69 & $1.413^{\circ}$ & $1.744^{\circ}$ \\
São João da Barra & 0,62 & 0,74 & $1.208^{\circ}$ & $1.014^{\circ}$ \\
\hline
\end{tabular}

Fonte: Banco de dados Firjan (2013).

As informações contidas na Tabela 2 confirmam o que Vianna da Cruz comenta sobre o problema do índice de desenvolvimento dessa região. Embora a grande maioria dos municípios apresentou melhora no índice de desenvolvimento municipal, a maior parte deles $(66 \%)$ não melhorou sua posição no Ranking Nacional do IFDM. Isso indica que o montante recebido dos royalties por esses municípios não refletiu decisivamente na melhora dos índices de desenvolvimento, se comparado com os municípios que não receberam esses recursos e que ficaram mais bem ranqueados em 2010. Essa constatação, mais uma vez, corrobora a afirmação de Vianna da Cruz (2005, p. 51) de que os royalties "não estão alterando qualitativamente o quadro de desigualdades, tanto sociais, quanto espaciais" dos municípios da região. 
A evidência de altos orçamentos e de índice de desenvolvimento insatisfatório nesses municípios aponta para o uso não planejado dos recursos dos royalties, com vistas ao desenvolvimento local e regional. Em rápida pesquisa na internet, por exemplo, são facilmente identificados casos que envolvem as administrações publicas desses municípios e o mau uso dos recursos orçamentários ${ }^{2}$. Aliado a isso, verifica-se, na Tabela 3, a dependência orçamentária de três municípios selecionados aos recursos dos royalties.

Tabela 3 - Participação dos Royalties na composição orçamentária dos
municípios selecionados na Região Norte Fluminense

\begin{tabular}{ccccccc}
\hline & \multicolumn{2}{c}{ São João da Barra } & \multicolumn{2}{c}{ Quissamã } & \multicolumn{2}{c}{ Campos de Goytacazes } \\
\cline { 2 - 7 } Ano & $\begin{array}{c}\text { Royalties } \\
\text { Valores } \\
\text { correntes, R\$) }\end{array}$ & $\begin{array}{c}\text { Royalties } \\
\text { /Orça- } \\
\text { mento* }\end{array}$ & $\begin{array}{c}\text { Royalties } \\
\text { (Valores } \\
\text { correntes, R\$) }\end{array}$ & $\begin{array}{c}\text { Royalties/ } \\
\text { Orça- } \\
\text { mento* }\end{array}$ & $\begin{array}{c}\text { Royalties } \\
\text { (Valores } \\
\text { correntes, R\$) }\end{array}$ & $\begin{array}{c}\text { Royalties/ } \\
\text { Orça- } \\
\text { mento* }\end{array}$ \\
\hline 1999 & $5.361 .638,18$ & $29 \%$ & $15.900 .697,84$ & $52 \%$ & $57.049 .478,33$ & N/D \\
2000 & $12.263 .029,70$ & $43 \%$ & $32.271 .214,42$ & $60 \%$ & $157.870 .442,17$ & $58 \%$ \\
2001 & $15.546 .845,80$ & $42 \%$ & $33.598 .003,95$ & $48 \%$ & $200.261 .211,38$ & N/D \\
2002 & $5.125 .955,15$ & $15 \%$ & $48.529 .278,63$ & $52 \%$ & $348.260 .944,92$ & $66 \%$ \\
2003 & $30.695 .016,17$ & $56 \%$ & $63.064 .726,98$ & $52 \%$ & $475.182 .177,54$ & N/D \\
2004 & $38.452 .755,73$ & $60 \%$ & $66.083 .508,29$ & $55 \%$ & $549.607 .310,98$ & $71 \%$ \\
2005 & $44.611 .137,74$ & $61 \%$ & $72.982 .583,90$ & $60 \%$ & $678.425 .571,67$ & $72 \%$ \\
2006 & $54.963 .765,14$ & $64 \%$ & $91.565 .639,24$ & $67 \%$ & $852.565 .850,92$ & $68 \%$ \\
2007 & $45.948 .760,90$ & $51 \%$ & $124.388 .669,93$ & $66 \%$ & $780.099 .183,21$ & N/D \\
2008 & $161.427 .752,79$ & $81 \%$ & $146.649 .730,18$ & $64 \%$ & $1.168 .642 .499,45$ & N/D \\
2009 & $168.329 .125,44$ & N/D & $90.969 .685,66$ & $54 \%$ & $993.167 .279,11$ & N/D \\
2010 & $203.028 .163,85$ & N/D & $90.508 .817,62$ & N/D & $1.016 .020 .729,34$ & N/D \\
2011 & $251.512 .931,02$ & N/D & $92.661 .381,55$ & N/D & $1.230 .645 .663,27$ & N/D \\
2012 & $190.953 .237,92$ & N/D & $95.080 .923,90$ & N/D & $1.110 .111 .241,09$ & N/D \\
\hline
\end{tabular}

* Porcentual dos Royalties na composição orçamentária do município.

N/D: Informação não disponível.

Fonte: Banco de Dados InfoRoyalties (2013), a partir de Agência Nacional do Petróleo e Secretaria do Tesouro Nacional.

Nos municípios de São João da Barra, Quissamã e Campos de Goytacazes a participação dos royalties na composição orçamentária supera os $50 \%$. E isso pode representar um grave déficit orçamentário e, inclusive, escassez de recursos, visto que a exploração do petróleo é uma atividade com prazo determinado, é uma atividade finita. Além do mais, atualmente vivencia-se um momento de discussões para a redefinição das normas que regem a distribuição dos royalties e compensações financeiras oriundas do petróleo no Brasil, muito em virtude de

\footnotetext{
${ }^{2}$ Ver: Talaska; Silveira (2008).
} 
requisições da sociedade em prol de uma distribuição mais equitativa dos royalties a todos os municípios brasileiros.

Nesse contexto, os municípios da região Norte Fluminense mostram-se como exemplo da complexidade que envolve o desenvolvimento regional nas condições atuais da economia capitalista. O crescimento econômico condicionado pelas atividades do setor petrolífero e os altos orçamentos verificados não se reproduzem necessariamente em desenvolvimento. $\mathrm{O}$ uso dos royalties na região se realiza de maneira individualizada, com desperdícios e investimentos que não geram novas receitas e nem promovem a inclusão social. São, em grande parte, investimentos desconexos da realidade do território.

É certo que a região Norte Fluminense alterou-se em decorrência da exploração do petróleo. O PIB dos municípios e os orçamentos municipais aumentaram, modificou-se a morfologia do tecido empresarial, alterou-se a oferta de postos de trabalho e a demografia, mas o destino da região ainda permanece incerto, como destacou Piquet (2010). O futuro da região permanece incerto porque a região continua amplamente dependente das petro-rendas.

\section{A redistribuição dos royalties do petróleo}

As novas descobertas de petróleo no pré-sal colocaram o Brasil diante de um quadro novo, que requer mudanças na forma de distribuição dos royalties aos municípios, estados e União. A redistribuição e revisão de alíquotas dos royalties foi proposta inicialmente no ano de 2009, quando se discutia o marco regulatório do pré-sal. A nova proposta de distribuição dos royalties do petróleo aumentaria o repasse de recursos para estados e municípios não produtores e diminuiria a parcela destinada aos estados e municípios onde há extração, portanto tornando mais equitativas as participações no resultado da exploração do petróleo, definidas no Art. 2, $\int 1^{\circ}$ da Constituição Federal de 1988.

O processo de discussão sobre a redistribuição dos royalties do petróleo resultou na redação do projeto de Lei do Senado $n^{\circ} 448 / 2011$, que modificava as Leis $\mathrm{n}^{\circ}$ 9.478/1997 e no 12.351/2010, para determinar novas regras de distribuição dos royalties e da participação especial, entre os entes da Federação, devidos em função da exploração de petróleo, gás natural e outros hidrocarbonetos fluidos, e para aprimorar o marco regulatório sobre a exploração desses recursos no regime de partilha.

Este projeto de Lei, após grandes debates na Câmara dos Deputados, no Senado e entre a sociedade brasileira, envolvendo, de um lado, a mobilização dos municípios confrontantes com os poços de petróleo, ou que possuem instalações de embarque e desembarque de petróleo e gás natural, e seus estados (os territórios privilegiados), e, de outro lado, a mobilização da grande maioria dos 
municípios brasileiros que entendiam que a distribuição deveria ser mais equitativa, culminou na sanção da Lei dos Royalties, Lei 12.734, de 30 de Novembro de 2012.

Por meio dessa Lei, a distribuição dos royalties do petróleo é alterada em relação ao rateio estabelecido pela Lei do Petróleo e pela regulamentação promovida pela ANP em 1998. Assim, a distribuição dos royalties do petróleo aos municípios, estados e União passa a ser realizado mediante as porcentagens especificadas no Quadro 1.

\section{Quadro 1 - Distribuição dos Royalties do Petróleo pela Lei 12.734/2012}

\begin{tabular}{|c|l|}
\hline \multicolumn{2}{|c|}{ Produção em terra, rios, lagos, ilhas lacustres ou fluviais } \\
\hline $20,0 \%$ & Estados (e DF) produtores \\
\hline $10,0 \%$ & Municípios produtores \\
\hline $5,0 \%$ & Municípios afetados por embarque e desembarque de petróleo e gás \\
\hline $25,0 \%$ & Fundo Especial, a ser distribuído entre estados e o Distrito Federal \\
\hline $25,0 \%$ & Fundo Espacial, a ser distribuído entre os municípios \\
\hline $15,0 \%$ & União \\
\hline \multicolumn{2}{|c|}{ Produção na plataforma continental, no mar territorial } \\
\multicolumn{2}{|c|}{ ou zona econômica exclusiva } \\
\hline $22,0 \%$ & Estados confrontantes \\
\hline $5,0 \%$ & Municípios confrontantes \\
\hline $2,0 \%$ & Municípios afetados por embarque e desembarque de petróleo e gás \\
\hline $24,5 \%$ & Fundo Especial, a ser distribuído entre estados e o Distrito Federal \\
\hline $24,5 \%$ & Fundo Espacial, a ser distribuído entre os municípios \\
\hline $22,0 \%$ & União \\
\hline
\end{tabular}

Fonte: Lei 12.734/2012.

Contudo, esta nova configuração de distribuição não incidirá sobre os territórios historicamente beneficiados com os recursos das petro-rendas de forma abrupta, mas, sim, de forma gradual. A Lei prevê, a partir de 2013, uma redução gradativa no percentual recebido por esses territórios até que em 2018 se consolide a distribuição constante no quadro. Assim, os municípios petro-rentistas ganham um fôlego orçamentário - com tempo definido - para promoverem sua diversificação econômico-produtiva, alterarem sua estrutura organizacional e planejarem o desenvolvimento local e regional no sentido de diminuírem suas dependências às petro-rendas.

Ainda em face da promulgação dessa Lei e da redistribuição dos royalties, os principais estados produtores de petróleo ingressaram no Supremo Tribunal Federal (STF) contra a nova legislação, alegando inconstitucionalidade. O STF, através da ministra Cármen Lúcia, decidiu suspender (em 18 de março de 2013) os 
efeitos da nova Lei até que seja divulgada a decisão sobre a constitucionalidade ou não da nova Lei.

Essa disputa judicial evidencia, ainda mais, a importância e a dependência dos estados e municípios produtores à arrecadação dos royalties. Desde 2009, ano em que se iniciaram os debates sobre a redistribuição, o montante arrecadado, segundo dados da ANP, superou 94 bilhões de reais, dos quais mais de 90\% ficaram com os estados do Rio de Janeiro e Espírito Santo. Anualmente, a previsão é que a arrecadação com royalties atinja valores superiores a 30 bilhões de reais, em virtude do preço do petróleo no mercado e do aumento da produção. Por isso, a nova regra, traz dois dilemas: i) a perda de recursos orçamentários de estados e municípios que estavam acostumados com realidades privilegiadas; e ii) uma nova realidade orçamentária para municípios que até então não possuem acesso aos recursos substanciosos dos royalties.

A normatização expressa pela Lei 12.734/2012 implica, então, na redistribuição dos royalties e participações especiais, havendo uma significativa redução da porcentagem de recebimento das petro-rendas pelos estados e municípios produtores, conforme demonstração no Quadro 2.

\section{Quadro 2 - Redução do montante dos royalties e participações especiais pagas aos municípios produtores de petróleo e gás natural}

\begin{tabular}{|l|l|l|}
\hline \multicolumn{1}{|c|}{ Petro-rendas } & \multicolumn{1}{|c|}{ Estados } & \multicolumn{1}{c|}{ Municípios } \\
\hline Royalties & Passará de $26,25 \%$ para $20 \%$ & Passará de $26,25 \%$ para $4 \%$ \\
\hline $\begin{array}{l}\text { Participações } \\
\text { Especiais }\end{array}$ & Passará de $40 \%$ para $20 \%$ & Passará de $10 \%$ para $4 \%$ \\
\hline
\end{tabular}

Fonte: Lei 9.478/1997, Decreto 2.455/1998 e Lei 12.734/2012.

Com relação aos estados e municípios não produtores, estes dividirão, tomando por base seus quantitativos populacionais, 54\% do montante dos royalties e 30\% das participações especiais pagas pelas empresas exploradoras do petróleo e gás natural no Brasil ${ }^{3}$.

\footnotetext{
${ }^{3}$ A título de exemplificação das implicações positivas que as petro-rendas podem gerar para os municípios não produtores de petróleo, buscou-se, nos cálculos realizados pela Confederação Nacional dos Municípios (CNM, 2012), o montante a ser recebido por uma região composta por 32 municípios no estado do Rio Grande do Sul. A região do Conselho Regional de Desenvolvimento Norte do Rio Grande do Sul (Corede Norte/RS) passaria a receber aproximadamente $\mathrm{R} \$ 15.000 .000,00$ anuais decorrentes do processo de redistribuição dos royalties. Esse valor é superior ao triplo daquele disponibilizado pelo governo do estado do Rio Grande do Sul para a região ( $\$ 4.556 .000,00)$, por meio da Consulta Popular 2013 - um
} 
Ainda no campo dos debates sobre a redistribuição das petro-rendas, em 9 de setembro de 2013, a presidente Dilma Roussef sancionou a Lei 12.858 que definiu a aplicabilidade dos recursos provenientes do pagamento dos royalties e participações especiais decorrentes da exploração do pré-sal brasileiro. Por meio dessa Lei, ficou definida a destinação de $25 \%$ dos royalties do pré-sal para a área de saúde e de 75\% para a área de educação. Esses recursos serão compostos pelos royalties e participações especiais decorrentes de campos de exploração cujas declarações de comercialidade tenham ocorrido a partir de 3 de dezembro de 2012.

Assim, a previsão do governo brasileiro é de que no ano de 2013 o repasse dos recursos provenientes dos royalties do pré-sal para a educação e a saúde seja de aproximadamente 700 milhões de reais, chegando a 19,96 bilhões de reais em 2022; entre 2013 e 2022, a previsão é de que ultrapasse os 112 bilhões de reais.

\section{O desafio da construção de um projeto de desenvolvimento regional}

A discussão da temática do projeto de desenvolvimento regional que, na primeira vista, pode parecer ser um tema simples, na realidade, emaranha uma grande complexidade, inclusive ao se considerar as implicações da redistribuição dos royalties do petróleo no território. Como pensar um projeto de desenvolvimento regional, utilizando as fontes dos recursos dos royalties, mas não tornando os territórios dependentes, exclusivamente, desse tipo de renda?

O economista chileno Sérgio Boisier, principalmente em seus escritos da década de 1990, indica alguns caminhos. Boisier (1994) expressa a ideia de que para a região se desenvolver ela precisa autoconstruir-se. Esse processo de autoconstrução se apoiaria no projeto político regional, produtor de coesão e de mobilização, dotando a região de estruturas políticas e administrativas, e no projeto cultural regional, produtor da percepção da identidade coletiva regional, capaz de transformar uma comunidade inanimada em outra organizada/animada, ou seja, capaz de mobilizar a região para construir seu próprio desenvolvimento.

Segundo Boisier (1994), para que a região tenha condições de construir o seu desenvolvimento torna-se necessária a efetivação de um processo de descentralização que eleve a capacidade da região em tomar suas próprias

importante e reconhecido instrumento de participação popular para a consensuação de metas e execução de políticas públicas que tratam do desenvolvimento da região - e, portanto, em muito poderia contribuir para proporcionar uma nova realidade aos municípios que compõe a região. Sobre o processo de formação e objetivos dos Conselhos Regionais de Desenvolvimento no Rio Grande do Sul e, em específico, à caracterização da região do Corede Norte, ver Talaska (2010). 
decisões, aumentando o poder político e maximizando a possibilidade de qualquer pessoa acessar os espaços institucionais e organizacionais ${ }^{4}$. Do mesmo grau de importância, Boisier (1994) indica ainda que o papel da formação profissional, da inovação e do avanço tecnológico nas pequenas e médias empresas é importante para o desenvolvimento regional endógeno.

Com base nesse contexto, a forma para avançar na direção do desenvolvimento regional parece estar relacionada a uma transformação na forma de se fazer governo nas regiões. As funções do governo regional devem abranger a condução de processos de negociações com o governo federal (para cima), com os agentes regionais (para os lados) e com os municípios e atores locais (para baixo), e em animar os atores locais e regionais, através de um processo de recirculação de informações e de atividades do tipo catalítico e sinergético, capaz de gerar novas iniciativas (BOISIER, 1994).

Assim, é categoricamente essencial a compreensão de que não existe uma única maneira de desenvolver uma região, existem, sim, alguns componentes que se mostram válidos durante a história. Estes, sem dúvida, estão relacionados com atitudes coletivas e com conduções sociais que favorecem a cooperação, a troca de ideias e o surgimento de sinergia, como salientado por Boisier (1994).

Esses componentes são retomados por Boisier (1996) quando o autor escreve o artigo "Em busca do esquivo desenvolvimento regional: entre a caixa-preta e o projeto político". Nesse texto, Boiser sistematiza algumas ideias já expostas em seus trabalhos anteriores para, posteriormente, incluir novos conceitos e pontos de vista sobre os fatores causais do desenvolvimento em escala territorial, indicando, nesse contexto, a necessidade da formulação de projetos políticos para a articulação entre tais fatores. Nessa perspectiva, Boisier processa a passagem do chamado triângulo do desenvolvimento regional para o hexágono do desenvolvimento regional (Figura 2), reiterando a importância da densificação das conexões entre seus vértices.

\footnotetext{
${ }^{4}$ Boisier aborda a descentralização, sobretudo, ao analisar o cenário latino americano, que, segundo ele, é caracterizado predominantemente e tradicionalmente por tomada de decisões verticalizadas, ou seja, de cima para baixo. Um exemplo de processo de descentralização, com vistas à participação das comunidades regionais nas decisões, é o caso dos Conselhos Regionais de Desenvolvimento no Rio Grande do Sul.
} 
Figura 2 - Hexágono do desenvolvimento regional

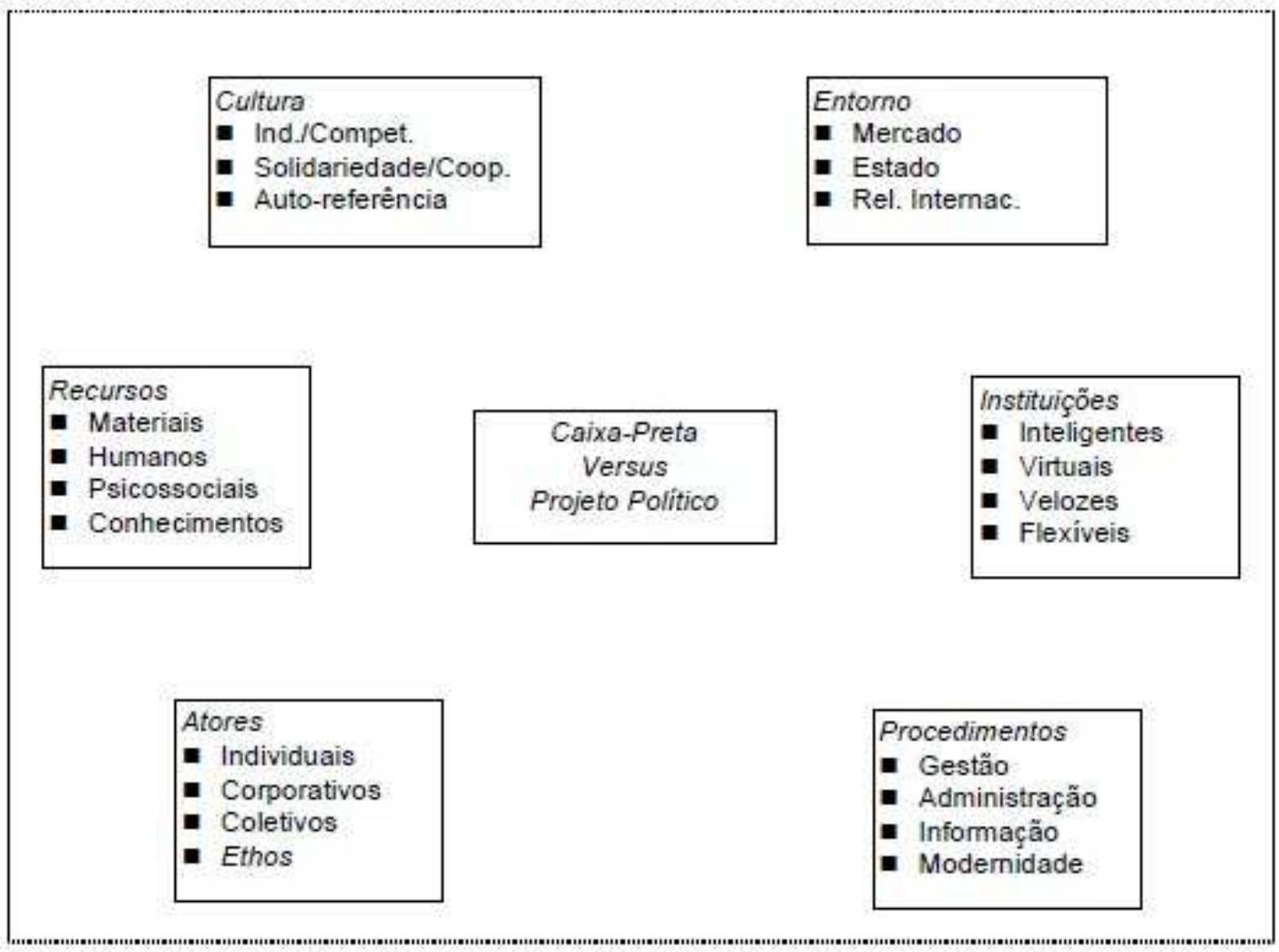

Fonte: Boisier (1996, p. 136).

A não existência a interação difusa ou aleatória desses seis elementos-chave (cultura, recursos, atores, procedimentos, instituições e entorno) na região origina o que Boisier (1996) denominou de caixa-preta do desenvolvimento, cujo conteúdo e funcionamento não são conhecidos.

Para além da existência dos seis elementos que formam o hexágono do desenvolvimento, Boisier (1996) destaca que o desenvolvimento de um território organizado depende do modo de articulação existente entre eles. Por isso, a importância é para que a articulação seja densa e inteligente, ao invés de difusa e aleatória. Assim, ao se buscar alavancar o desenvolvimento de um território organizado, deve-se avaliar a estruturação dos elementos e a articulação entre eles. Para isso, a tarefa básica é a de modernizar seus componentes e gerar um projeto coletivo de desenvolvimento que articule e direcione. Para tanto, se mostra significativamente importante a formação de um quadro qualificado de profissionais de desenvolvimento regional. Estes podem atuar na compreensão da organização socioespacial da região e propriamente no planejamento do seu desenvolvimento. 


\section{As petro-rendas e o desenvolvimento regional}

Como pensar a utilização das rendas do petróleo no contexto da elaboração de um projeto de desenvolvimento de uma região? A resposta a essa questão está, em grande parte, vinculada a formação do hexágono do desenvolvimento regional proposto por Sérgio Boisier.

O que se observa no Norte Fluminense é que a região dispõe de um montante de volumosos recursos financeiros provenientes dos royalties. Esses recursos, por si só, não estão proporcionando desenvolvimento à região, ou, ao menos, não nos termos esperados.

Através das petro-rendas, as prefeituras viram um rápido crescimento nas suas receitas orçamentárias, embora não houvesse estudo de impacto ou planejamento para a utilização destes recursos, não estando preparadas para a sua aplicação. Pode ser notado que em alguns destes municípios estas novas receitas logo se tornaram as principais fontes de recursos, fazendo com que, desta forma, deixassem de buscar suas próprias receitas de formas tradicionais, o que criou, assim, grande dependência dos recursos provenientes dos royalties.

Nota-se, que historicamente - período 1998 a 2012 -, esses recursos direcionados aos cofres públicos das prefeituras e incorporados ao orçamento municipal acabaram possuindo certa flexibilidade de aplicação. Isso faz com que "o grupo político dominante local acumule um poder desmesurado, considerando-se o poder proporcionado pelo volume de recursos controlados." (VIANNA DA CRUZ, 2005, p. 95). Nesse tocante, observa-se que os recursos provenientes dos royalties são controlados, na região Norte Fluminense, de forma individualizada, resultando em investimentos que não se refletem na alteração do cenário socioeconômico regional, amplamente assentado nas atividades petrolíferas. E acrescenta-se a isso a falta de políticas e resultados ao desenvolvimento endógeno da região.

Construir socialmente uma região, conforme a explicação de Boisier, significa

potencializar sua capacidade de auto-organização, transformando uma sociedade inanimada, segmentada por interesses setoriais, pouca perspectiva de sua identidade territorial e definitivamente passiva, em outra, organizada, coesa, consciente de sua identidade, capaz de mobilizar-se em torno de projetos políticos comuns, ou seja, capaz de transformar-se em sujeito de seu próprio desenvolvimento (ETGES, 2001, p. 362).

Assim, pondera-se que a aplicação das petro-rendas - seja de maneira direta ou indireta - está promovendo o aumento do nível real de investimentos nos 
municípios da região Norte Fluminense. Entretanto, a centralização nos processos decisórios $^{5}$, ou seja, a falta da participação da população, aliada à falta do conhecimento das particularidades territoriais, em decorrência da não consideração de um quadro de profissionais altamente qualificados em planejamento para o desenvolvimento local e regional, faz com que os administradores públicos direcionem investimentos que nem sempre chegam onde devem chegar e não atendam quem deveriam atender. O que, por conseguinte, não produz os resultados esperados.

Assim, é indispensável, como afirmou Etges (2005, p. 54) que se insista "na necessidade de um conhecimento sistemático da realidade, mediante o tratamento analítico do território, interrogando-o a propósito de sua própria constituição no momento histórico atual".

Entende-se, desse modo, que a análise e a compreensão da realidade do território - de sua organização socioespacial, suas relações, contradições e interdependências com outros agentes regionais - e a busca pela criação de um plano político de desenvolvimento, facilitaria a inversão das características geradoras de desagregação social, possibilitando a melhoria da qualidade de vida de toda a população envolvida. Isso porque,

quanto mais próxima esta organização for da perspectiva territorial, mais estreita será a relação com a natureza, no sentido de conhecer e respeitar seus limites [...] uma vez que estará voltada ao respeito e a integridade de todas as formas de vida, inclusive a humana (ETGES, 2005, p. 54).

Percebe-se, então, que o desafio da busca pela criação e consolidação de um projeto de desenvolvimento regional que tenha o território como enfoque principal, torna-se essencial. Um projeto que reúna os eixos propostos no hexágono do desenvolvimento regional de forma articulada estrategicamente para a promoção da coesão social em torno de propósitos comuns à população envolvida possibilitaria à região Norte Fluminense deixar de lado a caixa-preta do desenvolvimento, cujo futuro todos desconhecem, e iniciar um novo rumo, onde as premissas tenderiam a ser o conhecimento da configuração territorial, a participação da população, a produção de uma identidade de autorreferência regional, a multiescalaridade, a animação dos atores regionais, a equidade, e, por

\footnotetext{
${ }^{5}$ Martins (1995, p. 11) ilustra o problema da centralização das tomadas de decisão em processos de desenvolvimento regional, dizendo que: "o homem não é confiável no poder e tende a identificar-se com o mesmo, tornando o povo não o destinatário final de seu serviço, mas servidor de seus interesses".
} 
fim, a interação densa, articulada e inteligente dos eixos do desenvolvimento regional, como apontado por Boisier.

\section{Considerações finais}

A região Norte Fluminense é uma região emblemática. Primeiro, por vivenciar uma realidade privilegiada durante um período bastante significativo de tempo. Segundo, por durante esse período não efetivar um projeto político de desenvolvimento que repercutisse em níveis mais elevados e equitativos de desenvolvimento. Terceiro, por não prever que os recursos que recebe, provenientes da exploração do petróleo e gás natural, poderiam diminuir ou mesmo se extinguir. Quarto, por não buscar, eficazmente, diversificação econômico-produtiva que a libertasse da dependência das petro-rendas. E quinto, por, mesmo em meio aos debates sobre a redistribuição dos royalties do petróleo à sociedade brasileira, pouco ter avançado na direção da elaboração de um verdadeiro projeto de desenvolvimento regional.

Nesse contexto, o debate acerca da redistribuição mais equitativa das rendas do petróleo entre os estados e municípios brasileiros contribuiu para trazer ao primeiro plano as inquietações de muitos pesquisadores - como Rosélia Piquet e José Vieira Vianna da Cruz - que dedicaram grande tempo de suas carreiras a interpretar o processo de desenvolvimento ou do não desenvolvimento de regiões privilegiadas. Esse debate também proporcionou e revigorou discussões sobre os aspectos importantes que envolvem a complexidade de se pensar e de se fazer acontecer o desenvolvimento.

Nesse particular, é absolutamente essencial a compreensão de que não existe receita exclusiva para o desenvolvimento. O que existe são elementos que precisam ser buscados e articulados para que, conjuntamente, possa-se construir o desenvolvimento. Note-se, o desenvolvimento de que se está falando, no contexto das condições atuais da economia capitalista, é um processo que precisa ser construído, ele dificilmente acontece por acaso e muito menos é implantado - tal como é concebido, equivocadamente, por parcela da sociedade.

A construção do desenvolvimento deve abranger a participação de um número máximo de atores da sociedade. Deve, com base na atuação de pessoal qualificado, compreender o funcionamento do território, identificando no contexto socioespacial e econômico, as potencialidades e vulnerabilidades, de modo que seja possível articular ideias e sinergias e promover alternativas que possam ser, quando consideradas ao nível local, ampliadas também ao nível regional, proporcionando, dessa forma, forças para que a região se mantenha coesa e consequentemente resistente às inúmeras ameaças do mundo globalizado. 
Assim, é extremamente importante que a disposição em se pensar o desenvolvimento seja realizada considerando as características territoriais - $\mathrm{O}$ território. Essa consideração contribui para que a construção do desenvolvimento das regiões torne-se, de fato, realidade. E, por conseguinte, possibilite o abandono da chamada caixa-preta do desenvolvimento, em que os elementos e os rumos não são esclarecidos, sendo, portanto, obscuros à comunidade regional e, propriamente, aos governos municipais e lideranças regionais.

Desse modo, ressalta-se que está na ordem do dia a necessidade de se pensar a construção de projetos de desenvolvimento, tal como defendido por Boisier no final do século passado. A simples alocação de recursos e realização de intervenções pontuais no território não necessariamente resulta em processo de construção de desenvolvimento - um exemplo claro é a região Norte Fluminense.

Considera-se, portanto, que não basta a constante busca por recursos monetários, advindos de impostos, royalties ou compensações financeiras, para que se construa o desenvolvimento. Considera-se, sim, necessária a identificação das particularidades e das potencialidades dos territórios que, em um processo participativo de planejamento, possam dotá-lo de atividades capazes de empregar os orçamentos - advindos das rendas do petróleo, por exemplo - de forma comprometida. Comprometimento com vistas ao melhoramento dos serviços de bem-estar da sociedade, à potencialização de componentes regionais e a um processo de integração regional, com organização territorial e mobilização dos agentes regionais para que as regiões autoconstruam-se.

\section{Referências}

ANP. Agência Nacional do Petróleo. (Brasil). Site institucional. Disponível em: <http://www.anp.gov.br>. Acesso em: 15 out. 2013.

BARBOSA, Décio Hamilton (Coord.). Guia dos Royalties do Petróleo e do Gás Natural. Rio de Janeiro, ANP, 2001. Disponível em: <http://www.royaltiesdopetroleo.ucam-campos.br>. Acesso em: 14 abr. 2008.

BOISIER, Sérgio. El discurso final: la gestión del cambio paradigmático y contextual. In: BOISIER, Sérgio. La construcción social del regionalismo latinoamericano (Escenas, discursos y actores). Revista del CLAD Reforma y Democracia, Caracas, n. 2, jul., 1994.

. Em busca do esquivo desenvolvimento regional: entre a caixa-preta e o projeto político. Planejamento e Políticas Públicas, IPEA, Brasília, n. 13, p. 111-145, jun., 1996. 
BRASIL. Lei $\mathbf{n}^{\text {o }} \mathbf{2 . 0 0 4}$ de 3 de outubro de 1953. Disponível em: <http://www2.camara.leg.br/legin/fed/lei/1950-1959/lei-2004-3-outubro-1953366242-publicacaooriginal-1-pl.html>. Acesso em: 1 jun. 2013.

. Lei no 7.453 de 27 de dezembro de 1985. Disponível em: <http://www.planalto.gov.br/ccivil_03/leis/1980-1988/L7453.htm>. Acesso em: 3 jun. 2013.

. Lei $\mathbf{n}^{\mathbf{0}} \mathbf{9 . 4 7 8}$ de 06 de Agosto de 1997. Disponível em: <http://www.planalto.gov.br/ccivil_03/leis/19478.htm>. Acesso em: 3 jun. 2013.

Decreto $\mathrm{n}^{\mathrm{o}} 2.455$ de 14 de Janeiro de 1998. Disponível em: <http://www.planalto.gov.br/ccivil_03/decreto/D2455.htm>. Acesso em: 3 jun. 2013.

. Lei $\mathrm{n}^{\mathrm{o}} \mathbf{1 2 . 7 3 4}$ de 30 de novembro de 2012. Disponível em: <http://www.planalto.gov.br/ccivil_03/_Ato20112014/2012/Lei/L12734.htm>. Acesso em: 3 jun. 2013.

. Lei $\mathrm{n}^{\mathrm{o}} 12.351$ de 22 de dezembro de 2010. Disponível em: <http://www.planalto.gov.br/ccivil_03/_Ato2007-2010/2010/Lei/L12351.htm $>$. Acesso em: 3 jun. 2013.

. Lei $\mathrm{n}^{\mathrm{o}} 12.744$ de 19 de novembro de 2012. Disponível em: <http://www.planalto.gov.br/ccivil_03/_Ato2011-2014/2012/Lei/L12744.htm >. Acesso em: 3 jun. 2013.

. Lei $\mathrm{n}^{\mathrm{o}} \mathbf{1 2 . 8 5 8}$ de 9 de setembro de 2013. Disponível em: <http://www.planalto.gov.br/ccivil_03/_Ato20112014/2013/Lei/L12858.htm>. Acesso em: 26 set. 2013.

CONFEDERAÇÃO NACIONAL DOS MUNICÍPIOS. Derrubada dos vetos dos royalties: os ganhos do seu município, 2012. Disponível em: <http://www.royalties.cnm.org.br/v4/v11/royalties/ganhos.asp>. Acesso em: 28 mai. 2013.

ETGES, Virginia Elisabeta. A região no contexto da globalização: o caso do Vale do Rio Pardo. In: VOGT, Olgário Paulo; SILVEIRA, Rogério L. L.(Orgs.). Vale do Rio Pardo: (re)conhecendo a região. Santa Cruz do Sul: Edunisc, 2001. p. 351365.

- Desenvolvimento regional sustentável: o território como paradigma. Redes, Santa Cruz do Sul, v. 10, n. 3, p. 47-55, set./dez., 2005. 
FIRJAM. Índice Firjan de Desenvolvimento Municipal, 2013. Disponível em: <http://www.firjan.org.br/ifdm>. Acesso em: 27 mai. 2013.

IBGE. Instituto Brasileira de Geografia e Estatística. Censo Demográfico. 2010. Disponível em: <http://www.ibge.gov.br/home/estatistica/populacao/censo 2010/default.shtm>. Acesso em 27 jun. 2013.

IBP. Instituto Brasileiro de Petróleo, Gás e Biocombustíveis. Informativo sobre o pré-sal. Disponível em: <http://www.ibp.org.br $/$ main.asp?View $=\%$ 7B9B8 DA9D4-2EE4-493E-80BD-138D94539E2B\%7D\&Team=\%7BCFA331ED-C04 7-4441-8EEC-946E4\%7D>. Acesso em: 29 mai. 2013.

INFOROYALTIES. Banco de dados sobre royalties do petróleo, 2013. Disponível em: <http://inforoyalties.ucam-campos.br>. Acesso em: 14 mai. 2013.

MARTINS, Ives Gandra da Silva. Curso de direito tributário. Belém: Centro de Extensão Universitária, 1995.

MINISTÉRIO DA FAZENDA. Um estudo sobre a aplicação dos royalties petrolíferos no Brasil. 200?. Disponível em: <http://www.fazenda.gov.br/spe/publicacoes/estudos/um_estudo_sobre_a_apli cacao_dos_royalties.pdf> Acesso em: 29 mai. 2013.

PETROBRAS Brasileiro S/A. Site institucional. Disponível em: <http://www.petrobras.com.br>. Acesso em: 16 mai. 2013.

PIQUET, Rosélia. Impactos da indústria do petróleo no Norte Fluminense. Oficina sobre impactos sociais, ambientais e urbanos das atividades petrolíferas: o caso de Macaé/RJ. Niterói: Universidade Federal Fluminense, 2010. Disponível em: <http://www.uff.br/macaeimpacto/OFICINAMACAE/pdf/11_Roselia Piquet.pdf>. Acesso em: 29 mai. 2013.

TALASKA, Alcione. Estrutura agrária e reconfiguração fundiária - o caso da Região do COREDE Norte/RS. 2010. 154f. Dissertação (Mestrado em Desenvolvimento Regional). Universidade de Santa Cruz do Sul, Santa Cruz do Sul, 2010.

TALASKA, Alcione; SILVEIRA, Diônifer. Territórios privilegiados e desenvolvimento regional. In: VII Bienal do Colóquio de Transformações Territoriais, 2008, Curitiba/PR. Anais... Curitiba: UFPR, 2008. 
VIANNA DA CRUZ, José Luis. Economia petrolífera e a reprodução das desigualdades no Norte Fluminense. In: VIANNA DA CRUZ, José Luis (Org.). Brasil, o desafio da diversidade: Experiências de desenvolvimento regional. Rio de Janeiro: Ed. Senac, 2005. p. 75-108.

Endereço para correspondência:

Alcione Talaska-talaska.alcione@gmail.com

Av. Independência, 2293, Bloco 10, Sala 1023

96815-900 Santa Cruz do Sul/RS, Brasil

Péricles Purper Thiele - periclespurper@gmail.com

Av. Independência, 2293, Bloco 10, Sala 1023

96815-900 Santa Cruz do Sul/RS, Brasil

Almir Arantes - almir.ski@hotmail.com

Av. dos Ingás, 3001

78550-000 Sinop/MT, Brasil

José Antonio Assumpcão Farias - jantonioafarias@hotmail.com

Rua Barros Cassal, 2255

97543-060 Alegrete/RS, Brasil

Camila Talaska-camilatalaska@unochapeco.edu.br

Rua Beloni Trombeta Zanin, 680E

89815-630 Chapecó/SC, Brasil

Luana KöblerLouzado - luana_louzado@hotmail.com

Av. Independência, 2293, Bloco 10, Sala 1023

96815-900 Santa Cruz do Sul/RS, Brasil 